\title{
Therapeutic Modulation of Plasmacytoid Dendritic Cells in Experimental Arthritis
}

\author{
Ramzi Nehmar, ${ }^{1}$ Ghada Alsaleh, ${ }^{1}$ Benjamin Voisin, ${ }^{2}$ Vincent Flacher, ${ }^{2}$ Alexandre Mariotte, ${ }^{1}$ \\ Victoria Saferding, ${ }^{3}$ Antonia Puchner, ${ }^{3}$ Birgit Niederreiter, ${ }^{3}$ Thierry Vandamme, ${ }^{4}$ \\ Gernot Schabbauer, ${ }^{5}$ Philippe Kastner, ${ }^{6}$ Susan Chan, ${ }^{6}$ Peggy Kirstetter, ${ }^{6}$ Martin Holcmann, ${ }^{7}$ \\ Christopher Mueller, ${ }^{2}$ Jean Sibilia, ${ }^{1}$ Seiamak Bahram, ${ }^{1}$ Stephan Blüml, ${ }^{3}$ and Philippe Georgel ${ }^{1}$
}

Objective. The role of plasmacytoid dendritic cells (PDCs) and type I interferons (IFNs) in rheumatoid arthritis (RA) remains a subject of controversy. This study was undertaken to explore the contribution of PDCs and type I IFNs to RA pathogenesis using various animal models of PDC depletion and to monitor the effect of localized PDC recruitment and activation on joint inflammation and bone damage.

Methods. Mice with $\mathrm{K} / \mathbf{B x N}$ serum-induced arthritis, collagen-induced arthritis, and human tumor necrosis factor transgene insertion were studied. Symptoms were evaluated by visual scoring, quantification of paw swelling, determination of cytokine levels by

Supported by institutional funding from INSERM, Strasbourg University, the Laboratoire d'Excellence TRANSPLANTEX (ANR-11LABX-0070 TRANSPLANTEX), the PRTS ANR program (SPIRALE), and Campus France (PHC Program Amadeus 33696WM).

${ }^{1}$ Ramzi Nehmar, PhD, Ghada Alsaleh, PharmD, PhD, Alexandre Mariotte, MS, Jean Sibilia, MD, PhD, Seiamak Bahram, MD, PhD, Philippe Georgel, PhD: Université de Strasbourg, INSERM, IRM UMR-S 1109, Fédération de Médecine Translationnelle de Strasbourg, Faculté de Médecine, and Fédération Hospitalo-Universitaire, OMICARE, Centre de Recherche d'Immunologie et d'Hématologie, Strasbourg, France; ${ }^{2}$ Benjamin Voisin, PhD, Vincent Flacher, PhD, Christopher Mueller, PhD: Université de Strasbourg, CNRS UPR 3572, Laboratory of Immunopathology and Therapeutic Chemistry/ Laboratory of Excellence MEDALIS, Institut de Biologie Moléculaire et Cellulaire, Strasbourg, France; ${ }^{3}$ Victoria Saferding, MS, Antonia Puchner, MS, Birgit Niederreiter, MS, Stephan Blüml, MD, PhD: Internal Medicine 3, Medical University of Vienna, Vienna, Austria; ${ }^{4}$ Thierry Vandamme, PhD: Université de Strasbourg, CNRS UMR 7199, Faculté de Pharmacie, Illkirch, France; ${ }^{5}$ Gernot Schabbauer, $\mathrm{PhD}$ : Center for Physiology and Pharmacology, Medical University of Vienna, Vienna, Austria; ${ }^{6}$ Philippe Kastner, PhD, Susan Chan, PhD, Peggy Kirstetter, PhD: Institut de Génétique et de Biologie Moléculaire et Cellulaire, Université de Strasbourg, INSERM U964, CNRS UMR 7104, Illkirch, France; ${ }^{7}$ Martin Holcmann, PhD: Comprehensive Cancer Center, Medical University of Vienna, Vienna, Austria.

Address correspondence to Philippe Georgel, PhD, Université de Strasbourg, 1 Place de l'Hôpital, Strasbourg 67085, France. E-mail:pgeorgel@unistra.fr.

Submitted for publication December 20, 2016; accepted in revised form July 25, 2017. enzyme-linked immunosorbent assay, and histologic analysis. Imiquimod-dependent therapeutic effects were monitored by transcriptome analysis (using quantitative reverse transcriptase-polymerase chain reaction) and flow cytometric analysis of the periarticular tissue.

Results. PDC-deficient mice showed exacerbation of inflammatory and arthritis symptoms after arthritogenic serum transfer. In contrast, enhancing PDC recruitment and activation to arthritic joints by topical application of the Toll-like receptor 7 (TLR-7) agonist imiquimod significantly ameliorated arthritis in various mouse models. Imiquimod induced an IFN signature and led to reduced infiltration of inflammatory cells.

Conclusion. The therapeutic effects of imiquimod on joint inflammation and bone destruction are dependent on TLR-7 sensing by PDCs and type I IFN signaling. Our findings indicate that local recruitment and activation of PDCs represents an attractive therapeutic opportunity for RA patients.

Rheumatoid arthritis (RA) is a chronic multifactorial autoimmune disease (1), and secondary autoinflammatory mechanisms are major contributors to its perpetuation (2). The disease etiology involves different cell types, including innate and adaptive immune cells, which, along with resident synovial fibroblasts, interact to initiate and maintain an inflammatory milieu in the affected joint (3). Our current understanding is that interaction between the genetic background and environmental factors triggers the disruption of tolerance to self antigens, which leads to activation of both B and T cells. This B and T cell activation in turn leads to a proinflammatory loop including cytokine production, aberrant adaptive response, neovascularization, and synoviocyte activation. To control or avoid this pathogenic interplay of cells in the synovium of RA patients, 
drugs that affect different cellular and/or molecular actors have been developed (4), and major successes have been obtained in the past 15 years $(5,6)$, especially with biologic agents that target various cytokines (7). These treatments, however, have serious side effects in some cases (4).

While currently available therapies aim to control the various actors in RA pathogenesis, dendritic cells (DCs), which are at the crossroads between innate and adaptive immune cells, have not received due attention as potential therapeutic targets. Of interest is a subpopulation of DCs, the plasmacytoid DCs (PDCs), which are defined by their capacity to secrete large amounts of type I interferons (IFNs). IFNs are inflammatory cytokines of paramount importance in the pathophysiology of many autoimmune or autoinflammatory diseases (8). However, while the involvement of type I IFNs in RA pathogenesis is substantiated by several observations, such as an association with singlenucleotide polymorphisms in genes like IFN regulatory factor 5 (IRF-5) or IRF-8 (9) or the presence of the so-called "IFN signature" in the peripheral blood cells of RA patients $(10,11)$, the precise effect of these cytokines remains a subject of controversy. This is particularly well evidenced by the dichotomy between the positive and promising action of type I IFNs administered intraarticularly in animal models (12) and the subsequent absence of biologic effects when these molecules were delivered in the context of unsuccessful clinical trials (13). Hence, the precise role of type I IFNs, either beneficial or detrimental in RA pathogenesis, remains a subject of debate. Therefore, the potential to target these cytokines or the cells that produce them (PDCs) in order to expand the spectrum of molecules that may be prescribed to RA patients is still largely unexplored, despite obvious medical needs (among RA patients, 30-40\% do not respond to biologic agents and complete remission is achieved in only $25-30 \%$ [4]) and clear evidence demonstrating the presence of PDCs in the synovium of RA patients (14).

The present study aimed to clarify this issue. In various mouse models of PDC depletion in which joint inflammation was triggered by arthritogenic $\mathrm{K} / \mathrm{BxN}$ serum transfer, we observed worsened symptoms, suggesting that PDCs exert protective functions in RA. We next showed that mobilization and activation of PDCs upon topical application of the Toll-like receptor 7 (TLR-7) ligand imiquimod induces a notable reduction in the inflammation and bone erosion seen in 3 different mouse models of RA. This effect is accompanied by local recruitment of PDCs and reduced neutrophil infiltrates in the joint, as revealed by flow cytometry and transcriptome analysis. Importantly, the beneficial effects of imiquimod require type I IFN signaling. These observations highlight the potential efficacy of imiquimod, a molecule approved by the Food and Drug Administration, and its possible future use as the first topical treatment for RA.

\section{MATERIALS AND METHODS}

Mice. Ikaros-deficient mice $\left(\mathrm{Ik}^{\mathrm{L} / \mathrm{L}}\right.$ mice) have been described previously (15). TLR- $7^{-1-}$ mice were provided by Lena Alexopoulou, $\mathrm{PhD}$ (Centre d'Immunologie de Marseille-Luminy, Marseille, France), BDCA2-DTR mice were obtained from Maria Sibilia, MD (Medical University of Vienna) with the agreement of Marco Colonna, MD (Washington University, St. Louis, MO), and IFNAR-1 ${ }^{-1-}$ mice were obtained from Rolf Zinkernagel, MD (University Hospital Zurich, Zurich, Switzerland). Mice used in all experiments were age and sex matched. Animals were maintained under pathogen-free conditions in the animal care facility of our laboratory (Institut d'Immunologie et d'Hématologie, Strasbourg, France). Human tumor necrosis factor (TNF)-transgenic mice were provided by George Kollias, MD (Biomedical Sciences Research Center Alexander Fleming, Vari, Greece) and maintained in the animal facility of the Medical University of Vienna.

Study approval. Handling of mice and experimental procedures were conducted in accordance with French law for the protection of laboratory animals. The procedures were approved by the Service Véterinaire de la Préfecture du BasRhin (Strasbourg, France) and by the Regional Ethics Committee for Animal Experimentation of Strasbourg University, under authorization number 01608.01. Experiments performed in Vienna were approved by the animal ethics committee of the Medical University of Vienna and comply with institutional guidelines (BMWF-66.009/0103-C/GT/2007 and BMWF-66.009/0241-II/3b/2011). For additional information on study methods, see Supplementary Methods, available on the Arthritis \& Rheumatology web site at http://onlinelibrary. wiley.com/doi/10.1002/art.40225/abstract.

Statistical analysis. To analyze the time-dependent evolution of several parameters (paw thickness, joint arthritis score, and weight), we calculated the area under the curve and used the Mann-Whitney nonparametric unpaired 2-tailed test to compare 2 independent groups using GraphPad 5.04 software. Similarly, interleukin-6 (IL-6) expression, quantitative reverse transcriptase-polymerase chain reaction (qRT-PCR) results, quantification of cell population, and OsteoMeasure data were analyzed by Mann-Whitney 2-tailed unpaired test. $P$ values less than 0.05 were considered significant.

\section{RESULTS}

PDC deficiency exacerbates joint inflammation in a serum-transfer model of arthritis. To evaluate the contribution of PDCs to RA pathogenesis, we first used a serum-transfer model of arthritis (in which $\mathrm{B}$ and $\mathrm{T}$ cells are dispensable) (16). In this model, arthritogenic 
$\mathrm{K} / \mathrm{BxN}$ serum was injected into control mice and $\mathrm{Ik}^{\mathrm{L} / \mathrm{L}}$ mice, which have a hypomorphic mutation that causes a deletion of peripheral PDCs, while myeloid cells (like neutrophils) and lymphoid cells (B, T, and natural killer cells) remain unaffected $(15,17)$. (See Supplementary Figures $1 \mathrm{~A}-\mathrm{C}$, available on the Arthritis \& Rheumatology web site at http://onlinelibrary.wiley.com/doi/10. 1002/art.40225/abstract.)

The severity of joint inflammation was evaluated by measurement of paw thickness. $\mathrm{Ik}^{\mathrm{L} / \mathrm{L}}$ mice exhibited a significant increase in joint swelling compared to controls from days 6 to 15 (Figure 1A). Visual scoring of the joints (considering redness and swelling) yielded similar results (Supplementary Figure 1D). Increased weight loss in $\mathrm{Ik}^{\mathrm{L} / \mathrm{L}}$ mice compared to controls (Figure 1B) additionally indicated that PDC depletion promoted more severe systemic effects in $\mathrm{Ik}^{\mathrm{L} / \mathrm{L}}$ mice upon serum transfer. These observations were confirmed by cytokine quantification showing increased IL-6 and IL$1 \beta$ gene expression in the paws of $\mathrm{Ik}^{\mathrm{L} / \mathrm{L}}$ mice at the peak of the response (on day 9) (Figures 1C and D) and augmented secreted IL-6 in the blood of mutant animals on days 5 and 9 (Figures $1 \mathrm{E}$ and F). Histologic examination was performed on day 9. (Representative tartrate-resistant acid phosphatase staining is shown in Figures $1 \mathrm{~K}$ and L.) Histologic analysis indicated increased inflammatory infiltrates, osteoclast numbers, and importantly, bone erosion in the paws of $\mathrm{Ik}^{\mathrm{L} / \mathrm{L}}$ mice (Figures 1G-I).

While the serum-transfer model of arthritis is a model of acute disease characterized by quick recovery, we observed lasting bone erosion in $\mathrm{Ik}^{\mathrm{L} / \mathrm{L}}$ mice 22 days after the induction of arthritis (Figure 1J). Of note, $\mathrm{Ik}^{\mathrm{L} / \mathrm{L}}$ mice did not spontaneously develop any obvious bone defects, as evidenced by an exhaustive bone morphometric analysis (Supplementary Table 1, available on the Arthritis \& Rheumatology web site at http:// onlinelibrary.wiley.com/doi/10.1002/art.40225/abstract). Furthermore, similar numbers of osteoclasts were obtained upon RANKL stimulation of bone marrow cells from wild-type and $\mathrm{Ik}^{\mathrm{L} / \mathrm{L}}$ mice (Supplementary Figure 1E), indicating that osteoclastogenesis is not affected by the Ikaros mutation. Finally, we also detected a population of infiltrating PDCs in the periarticular tissue of control mice, but not $\mathrm{Ik}^{\mathrm{L} / \mathrm{L}}$ mice, with serum-transfer arthritis on day 10 (Supplementary Figures $1 \mathrm{~F}-\mathrm{I})$. (These were $\mathrm{CD} 45+\mathrm{B} 220^{\mathrm{low}} \mathrm{PDCA} 1+$ cells, which also stain with anti-CCR9 antibody, but not anti-Siglec $\mathrm{H}$ antibody [results not shown].) Of note, increased immune cell $(\mathrm{CD} 45+)$ infiltrate, of which neutrophils are likely the majority (18), was observed in $\mathrm{Ik}^{\mathrm{L} / \mathrm{L}}$ mice compared to wild-type mice
(Supplementary Figure 1H). Taken together, these data indicate that the presence of PDCs is important to limit or resorb the joint inflammation triggered by serum transfer.

To further analyze the role of PDCs, we used 2 different ablation methods. First, mice were injected with $120 \mathrm{G} 8$ monoclonal antibody (mAb) (19), which is specific for bone marrow stromal antigen 2 (tetherin/ CD317), predominantly expressed by mouse PDCs (20), and then inflammatory arthritis was examined following $\mathrm{K} / \mathrm{BxN}$ serum transfer. Paw swelling was significantly increased in mice receiving 4 injections of $120 \mathrm{G} 8 \mathrm{mAb}$ compared to those in which a control isotype antibody was injected (Supplementary Figure 2A, available on the Arthritis \& Rheumatology web site at http://onlinelibrary. wiley.com/doi/10.1002/art.40225/abstract). Serum IL-6 levels quantified 5 days after arthritis induction were increased in 120G8-treated mice compared to controls (Supplementary Figure 2B). However, histologic analysis did not reveal marked differences between PDCdepleted and control animals (Supplementary Figures $2 \mathrm{C}-\mathrm{G}$ ), which might be related to the resistant population of PDCs (B220+PDCA1 $+\mathrm{CD} 11 \mathrm{c}+)$ remaining after injections of 120G8 mAb (Supplementary Figures 2H and I) or, alternatively, to the consumption of complement caused by the iterative mAb injections.

Indeed, inflammation in the serum-transfer models of arthritis is particularly complement dependent (21). To circumvent this, we induced PDC ablation in BDCA2-DTR-transgenic mice (22). Using this approach, we first noticed that 5 successive injections of diphtheria toxin (on days $0,2,4,6$, and 8) partially phenocopied the $\mathrm{Ik}^{\mathrm{L} / \mathrm{L}}$ mutation. Indeed, a significant increase in paw swelling (Supplementary Figure 3A) and systemic IL-6 secretion on day 5 (Supplementary Figure 3B) was observed in DTR-transgenic mice upon diphtheria toxin injection. However, qRT-PCR quantification of IL- 6 and IL- $1 \beta$ transcripts on day 9 did not show any difference between control and BDCA2-DTR mice (Supplementary Figure 3C). Accordingly, this protocol, although efficient, did not enable PDC depletion as extensive as that seen in in $\mathrm{Ik}^{\mathrm{L} / \mathrm{L}}$ mice (Supplementary Figures 3D and E). Therefore, consistent with our previous analysis of 120G8-depleted mice, BDCA2-DTRtransgenic animals did not exhibit enhanced arthritis characteristics upon histologic analysis (Supplementary Figures $3 \mathrm{~F}-\mathrm{H}$ ). Taken together, these data suggest a protective role of PDCs in inflammatory arthritis.

Dampened inflammation and reduced bone destruction upon PDC recruitment and activation in mouse models of RA. We next sought to recruit and activate PDCs with the aim of controlling experimental 
A

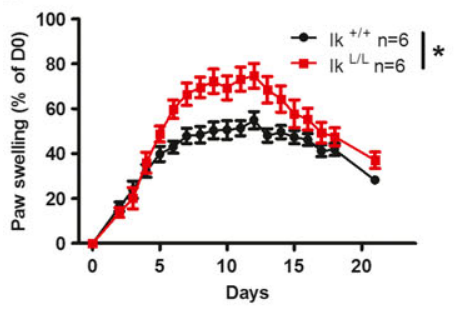

C

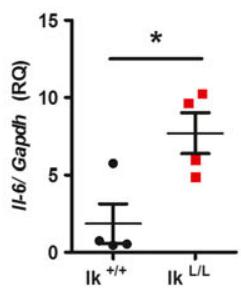

D

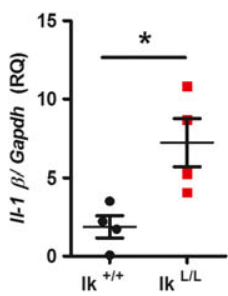

E
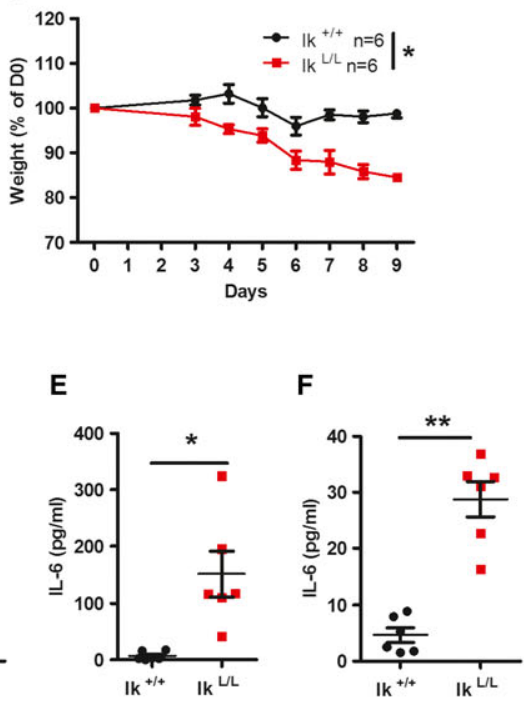

H

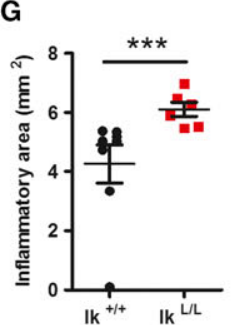

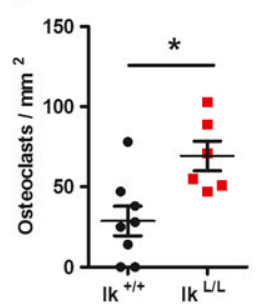

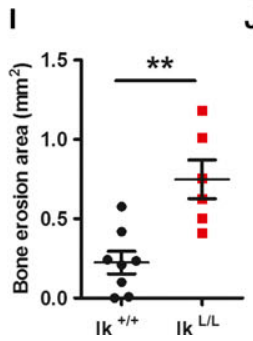

$J$

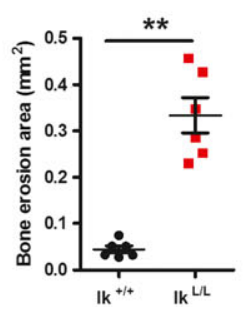

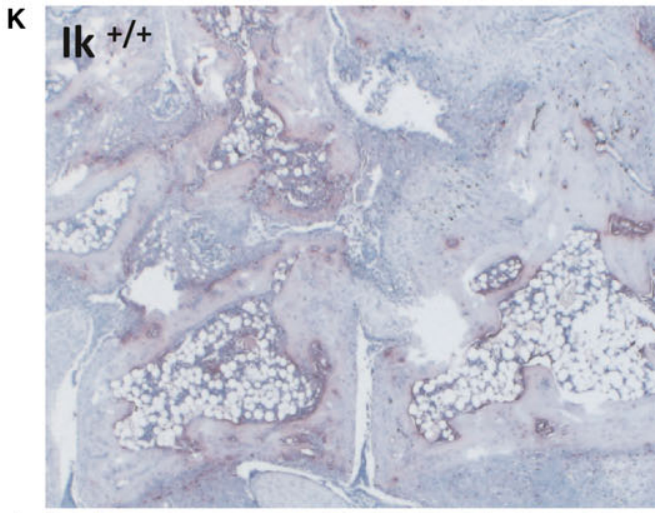

L

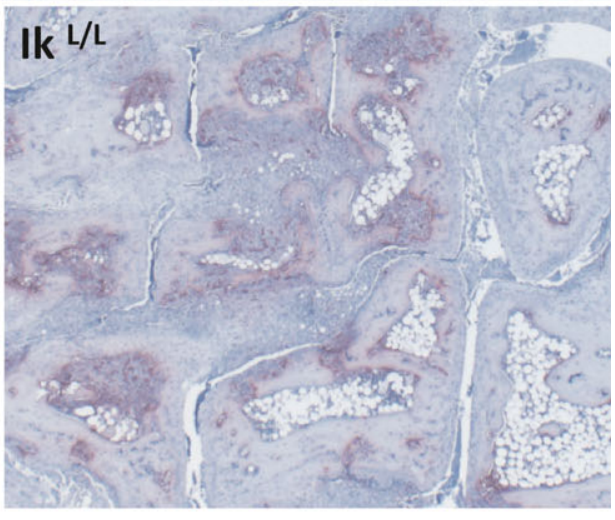

Figure 1. Enhanced arthritis symptoms in Ikaros mutant $\left(\mathrm{Ik}^{\mathrm{L} / \mathrm{L}}\right)$ mice upon $\mathrm{K} / \mathrm{BxN}$ serum transfer. A, Clinical quantification of paw swelling in wild-type and $\mathrm{Ik}^{\mathrm{L} / \mathrm{L}}$ mice with serum-transfer arthritis. $\mathbf{B}$, Effect of serum-transfer arthritis on the weight of wild-type and Ik ${ }^{\mathrm{L} / \mathrm{L}}$ mice. In $\mathbf{A}$ and $\mathbf{B}$, values are the mean \pm SEM. D0 = day 0. C and D, Relative quantification (RQ) of interleukin-6 (IL-6) (C) and IL-1 $\beta$ (D) expression in the paws of wild-type mice $(\mathrm{n}=4)$ and $\mathrm{Ik}^{\mathrm{L} / \mathrm{L}}$ mice $(\mathrm{n}=4)$ by quantitative reverse transcriptase-polymerase chain reaction 9 days after serum-transfer arthritis induction. $\mathbf{E}$ and $\mathbf{F}$, Quantification of serum IL-6 in wild-type mice $(\mathrm{n}=6)$ and $\mathrm{Ik}^{\mathrm{L} / \mathrm{L}}$ mice $(\mathrm{n}=6)$ by enzyme-linked immunosorbent assay 5 days $(\mathbf{E})$ and 9 days (F) after serum-transfer arthritis induction. G-I, Histomorphometric quantification of the area of inflammation (G), number of osteoclasts $(\mathbf{H})$, and bone erosion area $(\mathbf{I})$ in the hind paws of wild-type mice $(\mathrm{n}=8)$ and $\mathrm{Ik}^{\mathrm{L} / \mathrm{L}}$ mice $(\mathrm{n}=6) 9$ days after serum-transfer arthritis induction. $\mathbf{J}$, Histomorphometric quantification of bone erosion in the hind paws of wild-type mice $(\mathrm{n}=8)$ and $\mathrm{Ik}^{\mathrm{L} / \mathrm{L}}$ mice $(\mathrm{n}=6) 22$ days after serum-transfer arthritis induction. In $\mathbf{C}-\mathbf{J}$, symbols represent individual mice; horizontal lines and error bars show the mean \pm SEM. K and $\mathbf{L}$, Representative images of tartrate-resistant acid phosphatase staining of the hind paws of wild-type mice $(\mathbf{K})$ and $\mathrm{Ik}^{\mathrm{L} / \mathrm{L}}$ mice $(\mathbf{L}) 9$ days after serum-transfer arthritis induction. Original magnification $\times 5{ }^{*}=P<0.05 ; * *=P<0.01 ; * * *=P<0.001$. Results are representative of at least 2 experiments.

inflammatory arthritis. Imiquimod, a TLR-7 agonist, has been shown to induce psoriasis-like lesions upon topical application via the recruitment and activation of PDCs $(23,24)$. We first tested the effect of a cream containing 5\% imiquimod in the serum-transfer arthritis model (see Supplementary Video, available on the Arthritis \& Rheumatology web site at http://onlinelibrary. wiley.com/doi/10.1002/art.40225/abstract). We observed that 2 topical applications of $0.75 \mu \mathrm{g}$ of imiquimod on the inflamed joints on days 4 and 9 significantly reduced swelling (Figures 2A and B). This was accompanied by a decrease in local IL-6 and IL-1 $\beta$ gene expression
(Figures 2C and D) and systemic IL-6 secretion (Figure $2 \mathrm{E}$ ). Of note, increased IFN $\beta$ secretion was also observed after application of imiquimod on day 5 (Figure $2 \mathrm{~F}$ ). This reduced inflammation enhanced bone quality, as seen by decreased erosion in the imiquimod-treated group compared to the vehicle-treated group (Figures $2 \mathrm{G}$ and $\mathrm{H})$.

Importantly, imiquimod application increased the population of periarticular PDCs in wild-type animals (compared to vehicle-treated mice, see Supplementary Figure $1 \mathrm{~F}$ ), but not in $\mathrm{Ik}^{\mathrm{L} / \mathrm{L}}$ mutant mice (Figures 2I-K), in which the treatment did not appear 

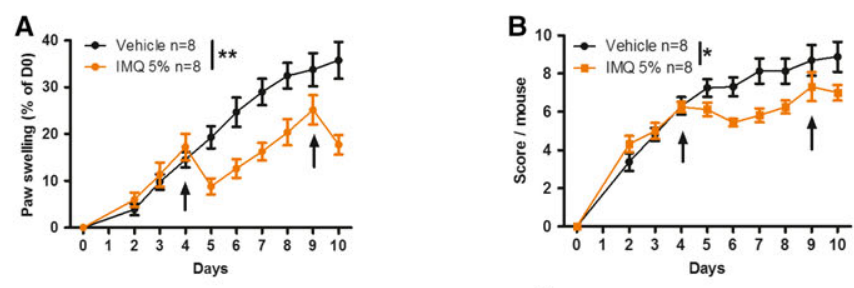

G
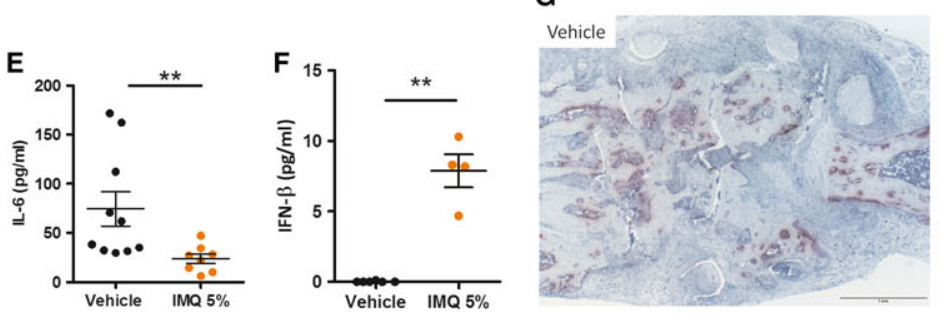
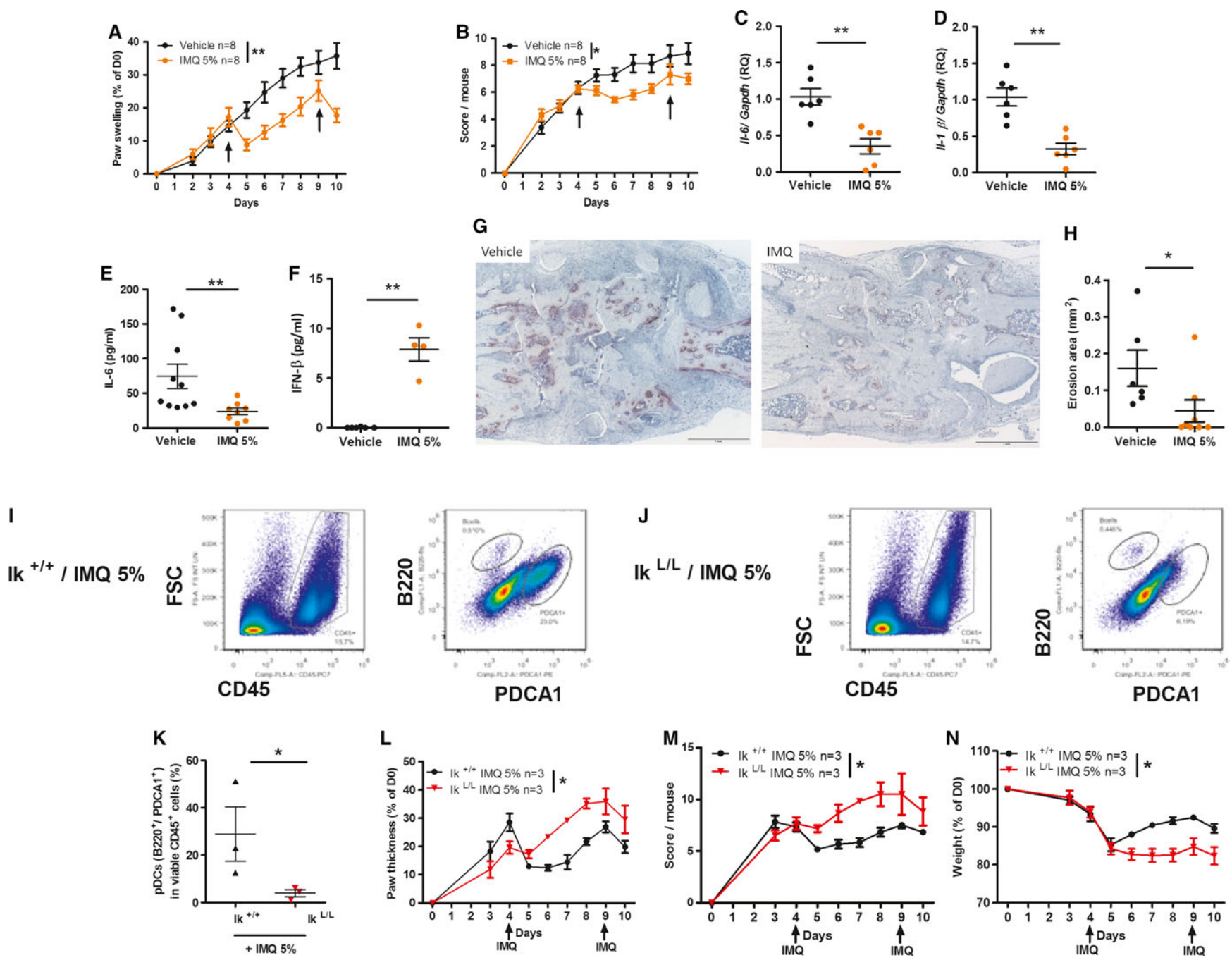

Figure 2. Reduction in joint inflammation and bone damage in serum-transfer arthritis upon topical application of imiquimod (IMQ). A-H show results for C57BL/6 wild-type mice ( $\mathrm{n}=6$ per group in $\mathbf{C}$ and $\mathbf{D} ; \mathrm{n}=10$ vehicle-treated mice and 8 imiquimod-treated mice in $\mathbf{E}$; $\mathrm{n}=6$ vehicletreated mice and 4 imiquimod-treated mice $\mathrm{n} \mathbf{F} ; \mathrm{n}=6$ vehicle-treated mice and 8 imiquimod-treated mice in $\mathbf{H})$. Animals were treated with topical application of 5\% imiquimod or a vehicle cream on the ankle joints of the front and hind paws on days 4 and 9. A and B, Paw swelling (A) and clinical score (B) in mice with serum-transfer arthritis. C and D, Relative quantification (RQ) of interleukin-6 (IL-6) (C) and IL-1 $\beta$ (D) expression in mouse paws by quantitative reverse transcriptase-polymerase chain reaction 9 days after serum-transfer arthritis induction. E, Quantification of serum IL-6 by enzyme-linked immunosorbent assay (ELISA) 9 days after serum-transfer arthritis induction. F, Quantification of serum interferon$\beta$ (IFN $\beta$ ) by ELISA 5 days after serum-transfer arthritis induction. G, Representative images showing tartrate-resistant acid phosphatase staining of mouse hind paws 9 days after serum-transfer arthritis induction. Bars $=500 \mu$. $\mathbf{H}$. Histomorphometric quantification of bone erosion in mouse hind paws 9 days after serum-transfer arthritis induction. I and $\mathbf{J}$, Representative flow cytometric analysis of joint-infiltrating plasmacytoid dendritic cells (PDCs; CD45+PDCA1+B220+) in wild-type $\left(\mathrm{Ik}^{+/+}\right)$mice $(\mathbf{I})$ and $\mathrm{Ikaros}^{\mathrm{L} / \mathrm{L}}\left(\mathrm{Ik}^{\mathrm{L} / \mathrm{L}}\right)$ mice $(\mathbf{J})$ treated with topical application of imiquimod 5\%. K, Quantification of joint-infiltrating PDCs in wild-type mice $(\mathrm{n}=3)$ and $\mathrm{Ik}^{\mathrm{L} / \mathrm{L}}$ mice $(\mathrm{n}=3)$ treated with topical application of imiquimod 5\%. $\mathbf{L}-\mathbf{N}$, Paw thickness $(\mathbf{L})$, visual score $(\mathbf{M})$, and weight $(\mathbf{N})$ in wild-type mice and $\mathrm{Ik}^{\mathrm{L} / \mathrm{L}}$ mice treated with topical application of imiquimod 5\%. In $\mathbf{A}, \mathbf{B}$, and $\mathbf{L}-\mathbf{N}$, values are the mean \pm SEM. In $\mathbf{C}-\mathbf{F}, \mathbf{H}$, and $\mathbf{K}$, symbols represent individual mice; horizontal lines and error bars show the mean \pm SEM. $*=P<0.05 ; * *=P<0.01$. Results are representative of at least 2 experiments. D0 $=$ day 0 .

to be effective either locally (as measured by paw swelling and visual score) or systemically (as measured by weight) (Figures $2 \mathrm{~L}-\mathrm{N}$ ). Furthermore, $\mathrm{Ik}^{\mathrm{L} / \mathrm{L}}$ mice treated with vehicle and those treated with imiquimod exhibited similar joint inflammation (Supplementary
Figures 4A-E, available on the Arthritis \& Rheumatology web site at http://onlinelibrary.wiley.com/doi/10.1002/art. 40225/abstract), although a weak and transient IFN response was noticed in $\mathrm{Ik}^{\mathrm{L} / \mathrm{L}}$ mice following imiquimod application (Supplementary Figure 4F), which can 


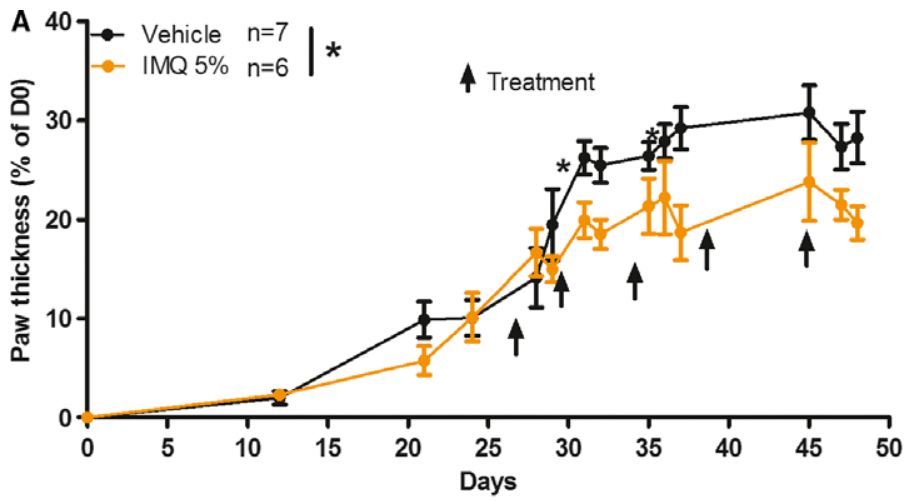

B

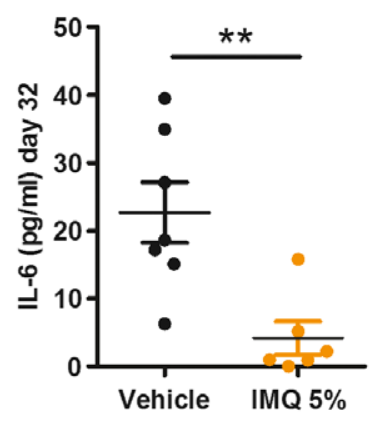

C

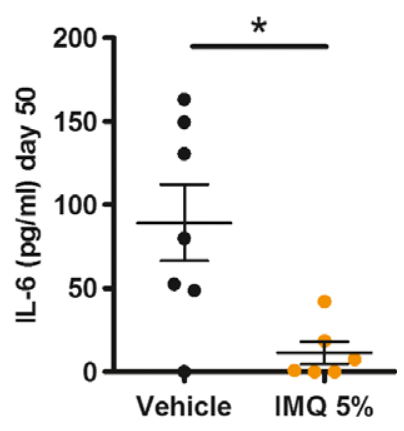

D
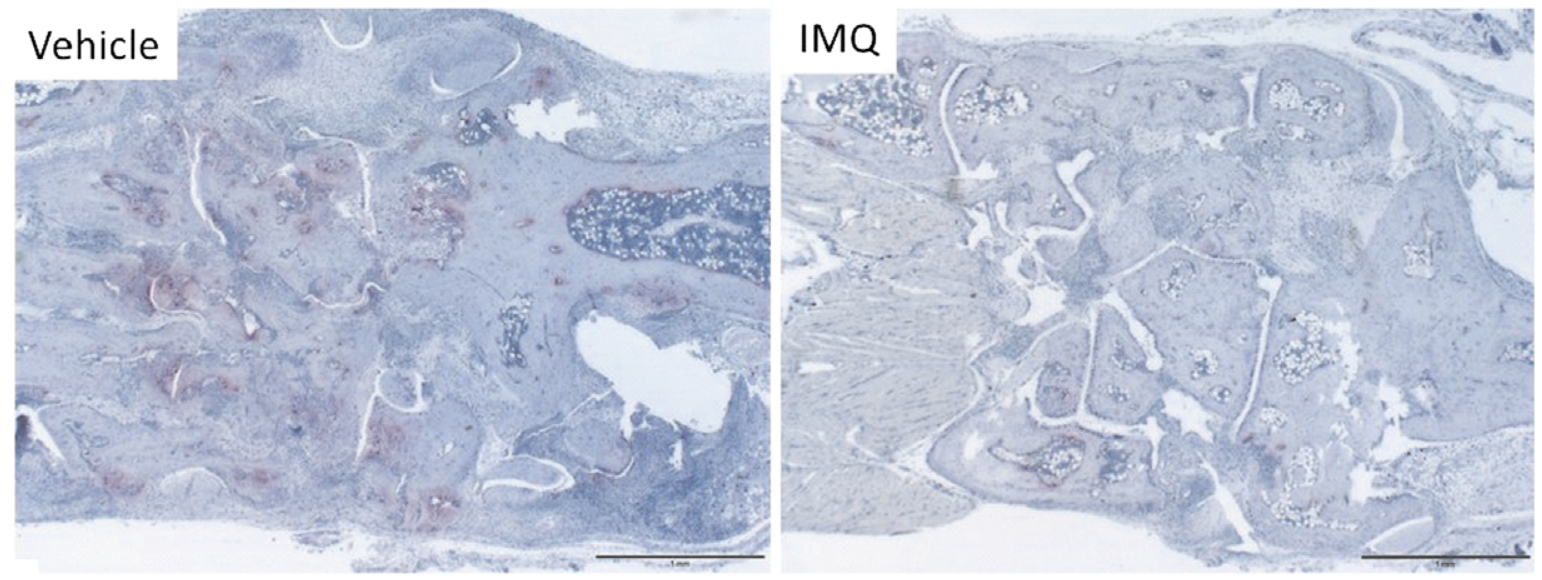

E

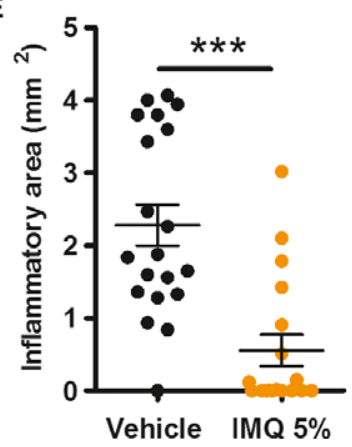

$\mathrm{F}$

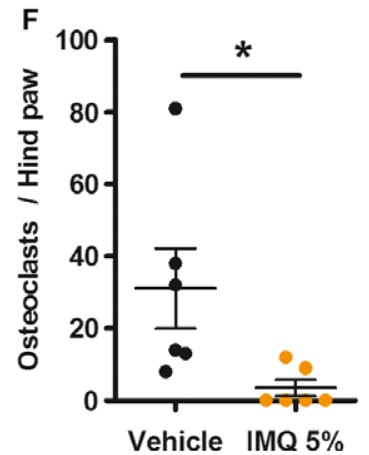

G

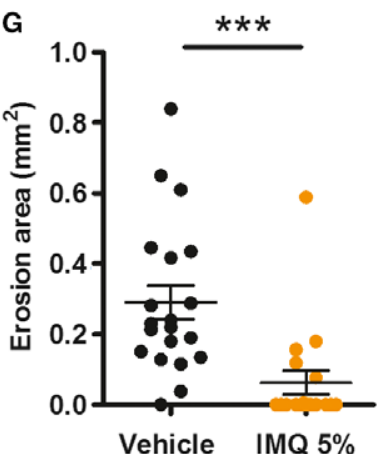

Figure 3. Reduction in joint inflammation and bone damage in DBA/1 mice with collagen-induced arthritis (CIA) by topical application of imiquimod (IMQ). A, Paw swelling in mice with CIA. Animals were treated with topical application of $5 \%$ imiquimod or a vehicle cream on the ankle joints of the front and hind paws on days 28, 31, 36, 41, and 46. Values are the mean \pm SEM. D0 = day 0 . B and $\mathbf{C}$, Quantification of serum interleukin-6 (IL-6) by enzyme-linked immunosorbent assay in vehicle-treated mice $(\mathrm{n}=7)$ and imiquimod-treated mice $(\mathrm{n}=6) 32$ days $(\mathbf{B})$ and 50 days (C) after induction of CIA. Symbols represent individual mice; horizontal lines and error bars show the mean \pm SEM. D, Representative images of tartrate-resistant acid phosphatase staining of the hind paws of vehicle-treated mice (left) and imiquimod-treated mice (right) 50 days after CIA induction. Bars $=500 \mu$. $\mathbf{E}-\mathbf{G}$, Histomorphometric quantification of the area of inflammation $(\mathbf{E})$, number of osteoclasts $(\mathbf{F})$, and bone erosion area (G) in the hind paws of vehicle-treated mice and imiquimod-treated mice 50 days after CIA induction. Symbols represent individual mice; horizontal lines and error bars show the mean \pm SEM. $*=P<0.05 ; * *=P<0.01 ; * * *=P<0.001$. Results are representative of at least 2 experiments.

reflect the presence of a small proportion of PDCs, or alternatively, the response of imiquimod-responding cells, such as conventional DCs, expressing low levels of TLR-7.
Next, we induced joint inflammation using serum transfer and treated mice (on days 4 and 9) in the right hind paw only. Paw thickness and visual score did not differ significantly between the contralateral (untreated) 
paws of treated mice and the paws of mice that received no imiquimod, thereby indicating that imiquimod exerts its maximal effects at the site of application (Supplementary Figures 5A-C, available on the Arthritis \& Rheumatology web site at http://onlinelibrary.wiley.com/doi/10. 1002/art.40225/abstract).

To expand these observations to alternative models of RA (18), we also tested the effect of iterative imiquimod applications in DBA/1 mice with collageninduced arthritis (CIA). We initiated imiquimod applications on day 28 , when the first signs of inflammation appeared, and then repeated the treatment 4 times (on days $31,36,41$, and 46). This led to a significant reduction in paw swelling compared to that in animals given the vehicle cream (Figure 3A and Supplementary Figure 6, available on the Arthritis \& Rheumatology web site at http://onlinelibrary.wiley.com/doi/10.1002/art.40225/ abstract). This observation was corroborated by decreased IL-6 secretion in the imiquimod-treated group at the peak of symptoms (on day 50) (Figure 3B). Histologic analysis of the paws revealed a marked reduction in the area of inflammation, the numbers of osteoclasts per hind paw, and, importantly, the bone erosion area (Figures $3 \mathrm{E}-\mathrm{G}$ ). In addition, imiquimod application induced a significant decrease in the production of anti-type II collagen antibodies on day 50 (Supplementary Figure 7, available on the Arthritis \& Rheumatology web site at http://onlinelibrary.wiley.com/doi/10. 1002/art.40225/abstract).

Finally, we administered serial imiquimod (or vehicle) applications to human TNF-transgenic mice, which are considered to be a relevant model of erosive arthritis (25). Each mouse received treatments on 1 hind paw. As seen in Figure 4, mice receiving imiquimod exhibited reduced arthritis symptoms, as monitored by histologic parameters.
Imiquimod-mediated therapeutic effects require type I IFN signaling. Having established the beneficial effect of topical imiquimod on joint inflammation, we aimed to describe its mechanism of action. First, we confirmed that topical application of imiquimod requires signaling through TLR-7 to induce its protective effects on joint inflammation. As shown in Supplementary Figure 8 (available on the Arthritis \& Rheumatology web site at http://onlinelibrary.wiley. com/doi/10.1002/art.40225/abstract), application of imiquimod on days 4 and 9 had no beneficial effects on local arthritis symptoms (increased joint swelling and score) (Supplementary Figures 8A and B) or systemic arthritis symptoms (weight loss) (Supplementary Figure $8 \mathrm{C}$ ) caused by $\mathrm{K} / \mathrm{BxN}$ serum transfer in TLR-7 ${ }^{-1-}$ animals. These observations correlate with the steady-state levels of circulating IL-6 seen on day 5 (Supplementary Figure 8D) and lack of PDC mobilization in the joints (Supplementary Figures $8 \mathrm{E}$ and F).

We gathered additional details by first using flow cytometry to analyze the effects of imiquimod application on the innate immune cell populations present in the periarticular tissue (gating strategy is shown in Supplementary Figure 9, available on the Arthritis \& Rheumatology web site at http://onlinelibrary.wiley.com/ doi/10.1002/art.40225/abstract). In addition, we performed a transcriptome analysis of this microenvironment. We noticed that application of imiquimod (but not the vehicle cream) to the joints of wild-type mice on days 4 and 9 following $\mathrm{K} / \mathrm{BxN}$ serum transfer drastically reduced the CD45+ immune cell infiltrate (Figure 5A). (See also Supplementary Figure 10, available on the Arthritis \& Rheumatology web site at http://on linelibrary.wiley.com/doi/10.1002/art.40225/abstract, for absolute numbers of cells present in the joint.) This is consistent with reduced swelling and a decrease in the
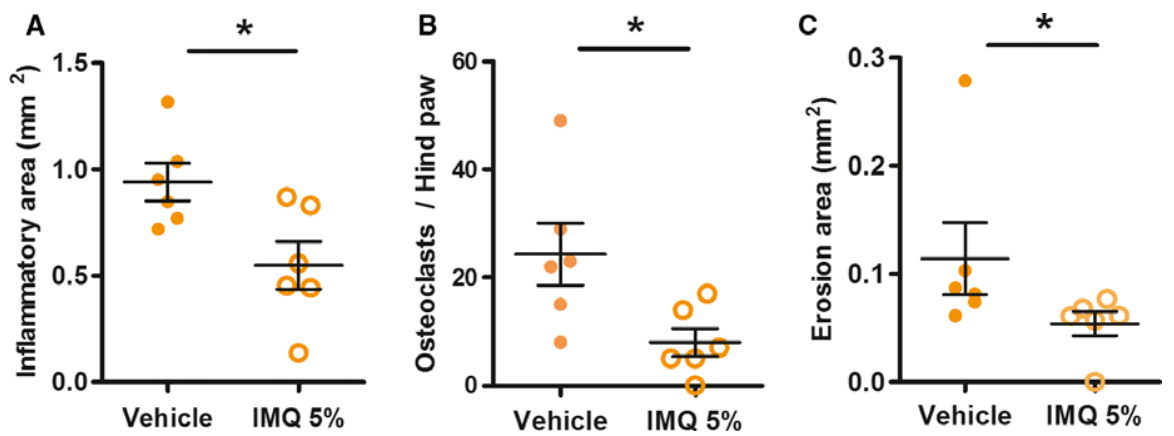

Figure 4. Reduced severity of arthritis symptoms in human tumor necrosis factor-transgenic mice treated with topical application of imiquimod (IMQ). Animals were treated with vehicle $(\mathrm{n}=6)$ or imiquimod 5\% $(\mathrm{n}=6)$. A, Histomorphometric quantification of the area of inflammation in vehicle-treated and imiquimod-treated mice. B, Number of osteoclasts per hind paw in vehicle-treated and imiquimod-treated mice. C, Bone erosion area in the hind paws of vehicle-treated and imiquimod-treated mice. Symbols represent individual mice; horizontal lines and error bars show the mean \pm SEM. ${ }^{*}=P<0.05$. Results are representative of at least 2 experiments. 

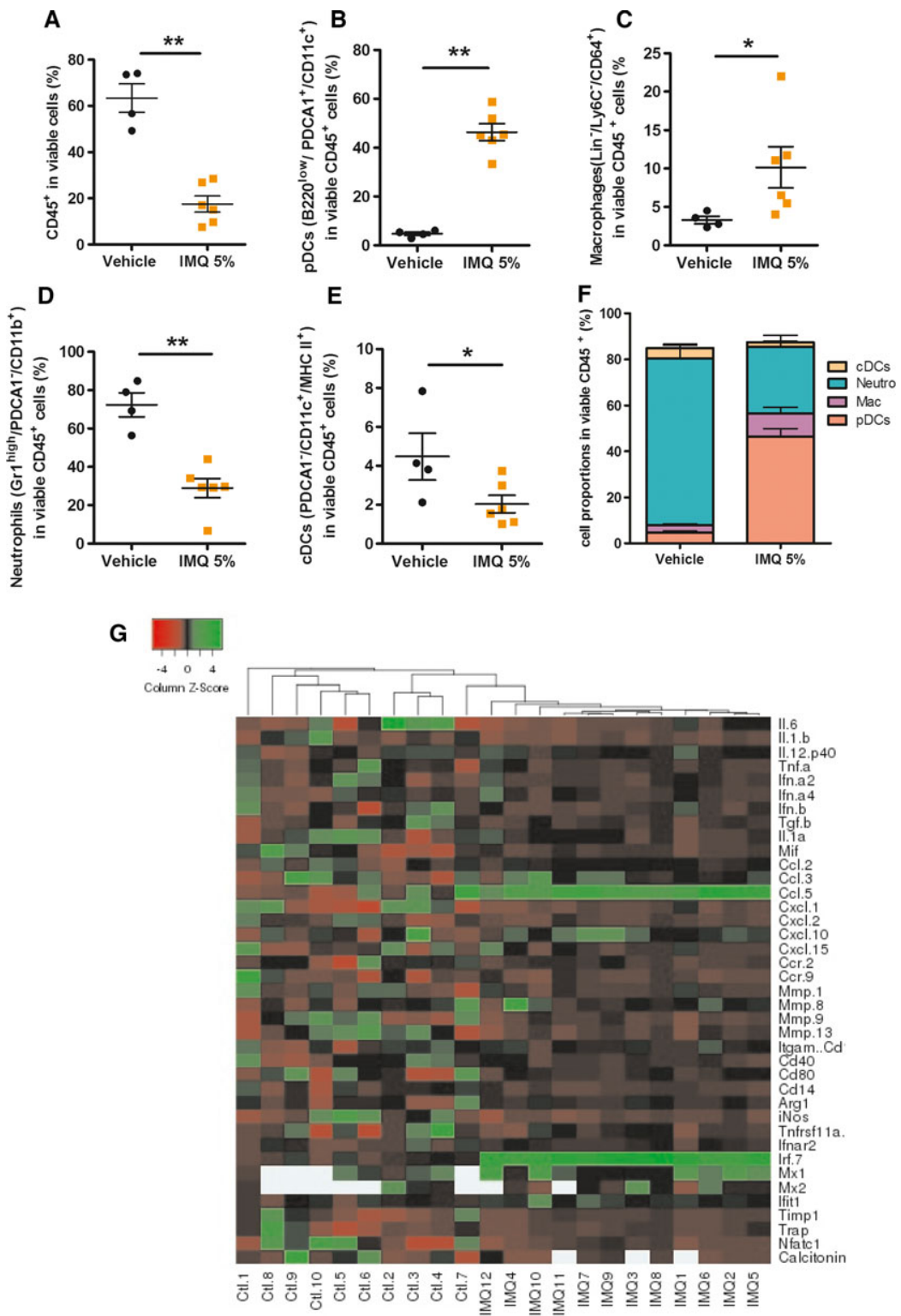

Figure 5. Induction of major cellular and transcriptional changes in the inflamed joints of mice with serum-transfer arthritis treated with imiquimod (IMQ). A, Quantification of immune (CD45+) cells by flow cytometry. B-E, Proportion of plasmacytoid dendritic cells (PDCs) (B), macrophages (Mac) (C), neutrophils (Neutro) (D), and conventional DCs (CDCs) (E) in the periarticular tissue of vehicle-treated C57BL/6 mice $(n=4)$ or imiquimod-treated C57BL/6 mice $(n=6) 9$ days after serum-transfer arthritis induction. In A-E, symbols represent individual mice; horizontal lines and error bars show the mean \pm SEM. F, Proportions of conventional DCs, neutrophils, macrophages, and PDCs in CD45+ cells in the periarticular tissue of vehicle-treated C57BL/6 mice $(n=4)$ and imiquimod-treated C57BL/6 mice $(n=6) 9$ days after serum-transfer arthritis induction. Bars show the mean \pm SEM. G, Heatmap depicting transcriptional profiling in the paws of vehicle-treated C57BL/6 mice $(\mathrm{n}=10)$ and imiquimod-treated $\mathrm{C} 57 \mathrm{BL} / 6$ mice $(\mathrm{n}=12) 9$ days after serum-transfer arthritis induction. $*=P<0.05 ; * *=P<0.01$.

expression of markers of inflammation (IL-6 and IL-1) (Figures 2C-E).

Furthermore, imiquimod induced the recruitment or the activation of PDCs, the proportion of which increased in the periarticular tissue of treated animals (Figures 5B and F), while absolute numbers remained steady (Supplementary Figure 10B). These changes were accompanied by reduced numbers of neutrophils (Figure 5D) and conventional DCs (Figure $5 \mathrm{E}$ ). Consistent with these observations, we found that imiquimod induced changes in transcriptome profiling, such as decreased expression of the genes encoding the neutrophil chemoattractants CXCL1 and CXCL2 (26), and increased expression of CCL2 and 

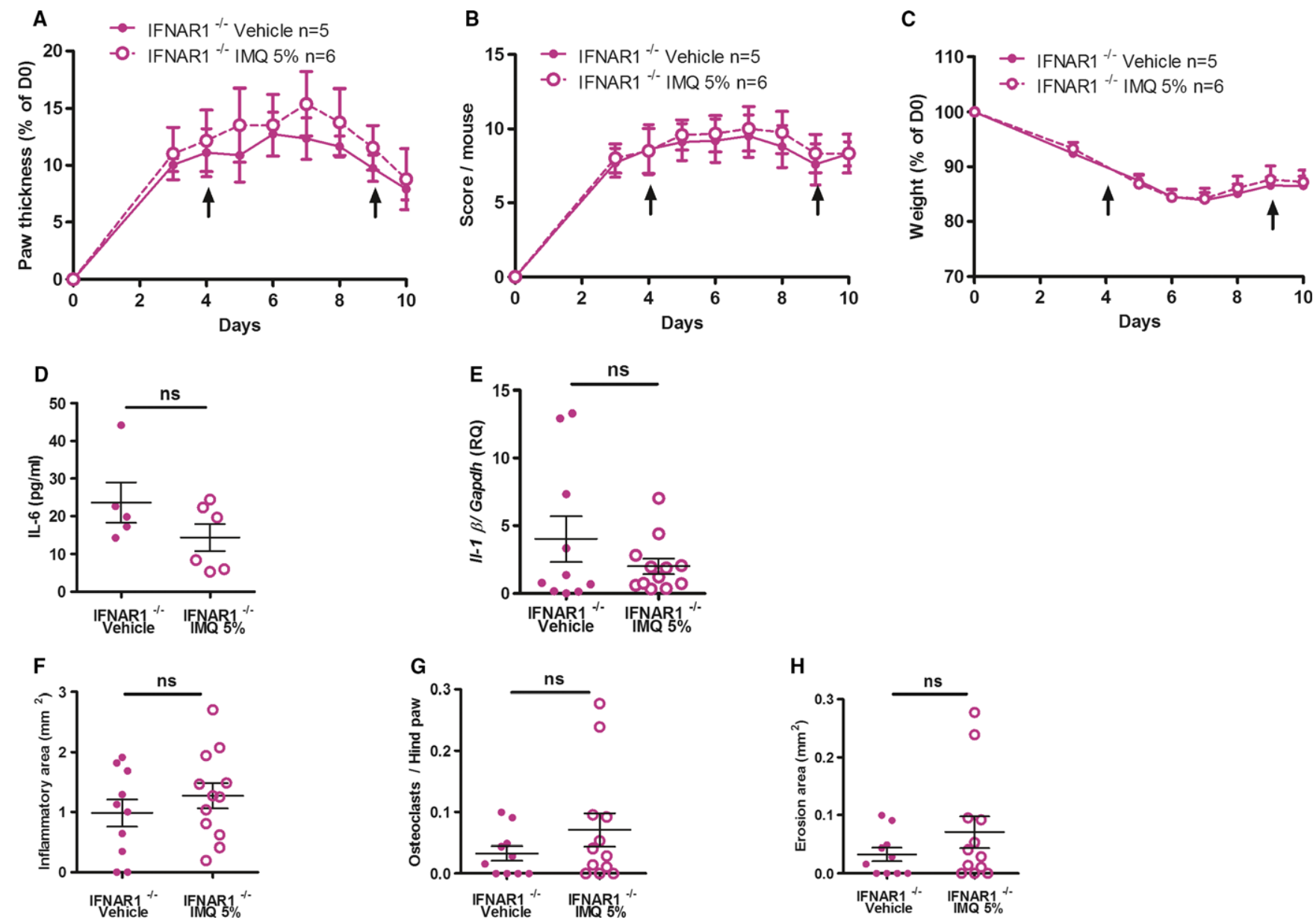

Figure 6. Type I interferon signaling is necessary for imiquimod (IMQ)-mediated antiinflammatory and bone-protective effects. A-C, Paw thickness (A), visual score (B), and weight (C) in IFNAR1 ${ }^{-1-}$ mice with serum-transfer arthritis treated with vehicle or imiquimod on days 4 and 9 after arthritis induction. D0 = day 0. D, Quantification of serum interleukin-6 (IL-6) by enzyme-linked immunosorbent assay in vehicle-treated IFNAR1 ${ }^{-/-}$ mice $(\mathrm{n}=5)$ and imiquimod-treated IFNAR1 ${ }^{-1-}$ mice $(\mathrm{n}=6) 5$ days after serum-transfer arthritis induction. E, Relative quantification (RQ) of IL$1 \beta$ transcripts in the paws of vehicle-treated IFNAR $1^{-/-}$mice $(\mathrm{n}=10)$ and imiquimod-treated IFNAR $1^{-/-}$mice $(\mathrm{n}=12)$ by quantitative reverse transcriptase-polymerase chain reaction 9 days after serum-transfer arthritis induction. F-H, Histomorphometric quantification of the area of inflammation $(\mathbf{F})$, number of osteoclasts $(\mathbf{G})$, and bone erosion area $(\mathbf{H})$ in the hind paws of vehicle-treated IFNAR $1^{-/-}$mice $(\mathrm{n}=10)$ and imiquimod-treated IFNAR1 ${ }^{-1-}$ mice $(\mathrm{n}=12) 9$ days after serum-transfer arthritis induction. In A-C, values are the mean \pm SEM. In $\mathbf{D}-\mathbf{H}$, symbols represent individual mice; horizontal lines and error bars show the mean \pm SEM. Results are representative of at least 2 experiments. NS $=$ not significant.

CCL5, the products of which attract monocytes (27) and PDCs (28) (Figure 5G and Supplementary Figure 11, available on the Arthritis \& Rheumatology web site at http://onlinelibrary.wiley.com/doi/10.1002/ art.40225/abstract).

Importantly, the ratio of arginase 1 to inducible nitric oxide synthase indicated that infiltrating macrophages of imiquimod-treated mice are likely polarized toward alternative activation (M2) (29), which is consistent with reduced IL-6, IL-1, and CD14 expression and reduced major histocompatibility complex class II staining in macrophages (Supplementary Figure 9D). Of note, a clear IFN signature was evidenced by increased levels of IRF-7 and several IFN-stimulated genes (ISGs), such as Mx-1, IFN-induced protein with tetratricopeptide repeats 1 , and CXCL10 transcription. The lack of changes in the expression of IFN $\beta$, IFN $\alpha 4$, and IFN $\alpha 2$ might reflect the fact that these genes are fast, non-lasting responders. Finally, the quantification of transcripts encoding matrix metalloproteinases (MMPs), which are important effectors participating in the bone damage following serum-transfer arthritis, confirms the protective effect of imiquimod. Indeed, expression of MMP-8 (whose knockout increases bone erosion, thereby classifying this MMP as "protective" [30]) was augmented by imiquimod application, while 
transcripts encoding the "pathogenic" MMP-9 (31) and MMP-13 (32) were slightly reduced.

Quantitative RT-PCR of a set of osteoclastrelated genes additionally showed reduced expression of the calcitonin receptor gene in the imiquimodtreated samples, consistent with the effects of the treatment on bone erosion, as seen on histologic examination. Transcripts encoding IL-10 remained below detection levels in this assay (results not shown). This analysis showed that topical application of imiquimod induced profound changes in the cellular cocktail that infiltrates the joint after serum-transfer arthritis induction. Most of these changes (such as M2 polarization of macrophages and the reduced proportion of neutrophils) likely account for the beneficial effects of imiquimod on joint inflammation and subsequent bone damage induced in mice with serum-transfer arthritis.

Finally, the transcriptomic "IFN signature" prompted us to evaluate the importance of type I IFN signaling in the antiinflammatory effects mediated by application of imiquimod. We examined the impact of imiquimod application in IFNAR ${ }^{-1-}$ mice upon $\mathrm{K} / \mathrm{BxN}$ serum transfer. The data demonstrated that absence of type I IFN signaling impairs imiquimod-dependent antiinflammatory effects, as determined by paw swelling, weight, IL-6 expression, and histologic features of the arthritic joints (Figure 6). Taken together, our findings indicate a stepwise scenario whereby the sequence imiquimod/TLR-7/PDCs/type I IFN creates an appropriate environment for dampening joint inflammation and reducing subsequent bone damage.

\section{DISCUSSION}

The role of type I IFNs in the pathogenesis of RA remains a matter of controversy (10). Several previous studies pointed to an association between increased type I IFN secretion and subsequent transcription of ISGs (the so-called "IFN signature" [33]) in some RA patients (34). This suggests that this cytokine family exerts proarthritogenic effects, which correlate with cases of disease induction in patients with hepatitis $\mathrm{C}$ virus treated with PEGylated IFN (35). However, several mouse studies have challenged this concept. For instance, IRF-7-deficient mice are resistant to serumtransfer arthritis (36), and several authors have reported beneficial effects of IFN $\beta$ injections in mice (12) or rhesus monkeys (37) after arthritis induction. This led to a first clinical trial involving a small number of patients (n =11) (38) whose promising results could not be reproduced when the number of subjects was scaled up $(\mathrm{n}=$ 209) (13). Furthermore, a pathogenic role of type I IFNs is also difficult to reconcile with the correlation between a reduction in PDCs and the severity of arthritis shown in mice (39) and in humans (40), since PDCs are the main source of type I IFNs. The most striking demonstration of the controversial role of type I IFNs in RA is perhaps illustrated by 2 publications from the same group reporting that IFNAR-knockout mice can either protect (41) or enhance (42) RA pathology, depending on the model.

In this study, using 3 models of PDC depletion, we provide substantial evidence for a protective role of PDCs in inflammatory arthritis (Figure 1 and Supplementary Figures 1-3). We also managed to mobilize these cells at the inflamed site using topical application of imiquimod, a TLR-7 ligand. Imiquimod is the active component of a Food and Drug Administrationapproved topical treatment for superficial basal cell carcinoma and external genital warts, a process which is also PDC dependent (28). This simple procedure exhibited remarkable efficacy for both resolution of inflammation and protection from bone damage. Importantly, we demonstrated that this protocol is efficient in 3 different models of arthritis characterized by different mechanisms of disease initiation and perpetuation (43): the $\mathrm{K} / \mathrm{BxN}$ serum-transfer model of arthritis, CIA, and human TNF-transgenic mice (Figures 2-4). Finally, our flow cytometry and transcriptome analyses (Figure 5) of periarticular tissues revealed that imiquimod application induces a TLR-7/PDC/type I IFN cascade that ultimately reduces the proportion of infiltrating neutrophils, the cytotoxic functions of which make them major contributors to RA pathology (44). This is accompanied by an increased number of macrophages, whose polarization toward an alternatively activated phenotype likely contributes to the maintenance of an antiinflammatory milieu.

Consistent with a previous report describing CpGmediated inhibition of serum-transfer arthritis (45), our data suggest that PDCs are majors players in the regulation of inflammatory reactions in the joint. While the precise mechanisms of the cellular cross-talk remain to be deciphered, both imiquimod- and CpG-mediated resolution of inflammatory arthritis appear to converge toward a reduction of the neutrophil infiltrate in the joint. A more thorough transcriptome analysis (using RNA sequencing) of the inflamed joint following imiquimod application is needed to identify signatures enabling the identification and activation status of the different innate immune cells present in this compartment (46). However, our work extends these observations beyond the innate immunity-dependent models of arthritis in mice (namely, $\mathrm{K} / \mathrm{BxN}$ serum transfer and human $\mathrm{TNF}$-transgenic mice) 
to the CIA model in which $\mathrm{T}$ and $\mathrm{B}$ cell activation is required. Furthermore, the present work points to an essential role of type I (and possibly type III [47]) IFN signaling in the protective effect of imiquimod following experimental arthritis. This is illustrated by the upregulation of the ISG CXCL10 which, through its antiangiogenic properties (48), may also participate in this therapeutic process. In addition, our data are consistent with recent observations that enabled a re-evaluation of the role of IFN $\beta$ and PDCs in the dampening of excessive inflammation occurring in various pathologic settings $(49,50)$.

Up to now, manipulation of DCs for therapeutic purposes has been accomplished by means of adoptive transfer, for instance, of PDCs, which confer recovery from experimental autoimmune encephalomyelitis (49), or of tolerogenic DCs in RA patients (51). While infusion of autologous tolerogenic DCs appears feasible, and possibly beneficial (although not yet demonstrated) in large joints, this expensive procedure is unlikely to be applicable to the ever-growing number of patients in developed countries. Furthermore, it does not appear suitable for smaller joints in which injections remain a very painful procedure. We believe that mobilization of PDCs upon topical application of imiquimod, although not devoid of risks (52), might represent an attractive, cost-effective, and efficient alternative for improving the management of RA. A future clinical trial should clarify this opportunity.

\section{ACKNOWLEDGMENTS}

We thank Marc Dalod and Elena Tomasello (Centre d'Immunologie de Marseille-Luminy, Marseille, France) for helpful advice.

\section{AUTHOR CONTRIBUTIONS}

All authors were involved in drafting the article or revising it critically for important intellectual content, and all authors approved the final version to be published. Dr. Georgel had full access to all of the data in the study and takes responsibility for the integrity of the data and the accuracy of the data analysis.

Study conception and design. Nehmar, Alsaleh, Voisin, Flacher, Mariotte, Saferding, Puchner, Niederreiter, Vandamme, Schabbauer, Kastner, Chan, Kirstetter, Holcmann, Mueller, Sibilia, Bahram, Blüml, Georgel

Acquisition of data. Nehmar, Alsaleh, Voisin, Flacher, Mariotte, Saferding, Puchner, Niederreiter, Vandamme, Schabbauer, Kastner, Chan, Kirstetter, Holcmann, Mueller, Sibilia, Bahram, Blüml, Georgel.

Analysis and interpretation of data. Nehmar, Alsaleh, Voisin, Flacher, Mariotte, Saferding, Puchner, Niederreiter, Vandamme, Schabbauer, Kastner, Chan, Kirstetter, Holcmann, Mueller, Sibilia, Bahram, Blüml, Georgel.

\section{REFERENCES}

1. Firestein GS. The disease formerly known as rheumatoid arthritis. Arthritis Res Ther 2014;16:114.

2. McGonagle D, McDermott MF. A proposed classification of the immunological diseases. PLoS Med 2006;3:e297.

3. McInnes IB, Schett G. The pathogenesis of rheumatoid arthritis. N Engl J Med 2011;365:2205-19.

4. Zampeli E, Vlachoyiannopoulos PG, Tzioufas AG. Treatment of rheumatoid arthritis: unraveling the conundrum. J Autoimmun 2015;65:1-18.

5. Smolen JS, Aletaha D. Rheumatoid arthritis therapy reappraisal: strategies, opportunities and challenges. Nat Rev Rheumatol 2015;11:276-89.

6. Burmester GR, Feist E, Dorner T. Emerging cell and cytokine targets in rheumatoid arthritis. Nat Rev Rheumatol 2014;10:77-88.

7. McInnes IB, Buckley CD, Isaacs JD. Cytokines in rheumatoid arthritis: shaping the immunological landscape. Nat Rev Rheumatol 2016;12:63-8.

8. Swiecki M, Colonna M. The multifaceted biology of plasmacytoid dendritic cells. Nat Rev Immunol 2015;15:471-85.

9. Messemaker TC, Huizinga TW, Kurreeman F. Immunogenetics of rheumatoid arthritis: understanding functional implications. J Autoimmun 2015;64:74-81.

10. Conigliaro P, Perricone C, Benson RA, Garside P, Brewer JM, Perricone R, et al. The type I IFN system in rheumatoid arthritis. Autoimmunity 2010;43:220-5.

11. Lopez de Padilla CM, Niewold TB. The type I interferons: basic concepts and clinical relevance in immune-mediated inflammatory diseases. Gene 2016;576:14-21.

12. Van Holten J, Reedquist K, Sattonet-Roche P, Smeets TJ, PlaterZyberk C, Vervoordeldonk MJ, et al. Treatment with recombinant interferon- $\beta$ reduces inflammation and slows cartilage destruction in the collagen-induced arthritis model of rheumatoid arthritis Arthritis Res Ther 2004;6:R239-49.

13. Van Holten J, Pavelka K, Vencovsky J, Stahl H, Rozman B, Genovese $\mathrm{M}$, et al. A multicentre, randomised, double blind, placebo controlled phase II study of subcutaneous interferon $\beta$ - 1 a in the treatment of patients with active rheumatoid arthritis. Ann Rheum Dis 2005;64:64-9.

14. Takakubo Y, Takagi M, Maeda K, Tamaki Y, Sasaki A, Asano T, et al. Distribution of myeloid dendritic cells and plasmacytoid dendritic cells in the synovial tissues of rheumatoid arthritis. J Rheumatol 2008:35:1919-31.

15. Allman D, Dalod M, Asselin-Paturel C, Delale T, Robbins SH, Trinchieri G, et al. Ikaros is required for plasmacytoid dendritic cell differentiation. Blood 2006;108:4025-34.

16. Korganow AS, Ji H, Mangialaio S, Duchatelle V, Pelanda R, Martin T, et al. From systemic T cell self-reactivity to organ-specific autoimmune disease via immunoglobulins. Immunity 1999;10:451-61.

17. Dumortier A, Kirstetter P, Kastner P, Chan S. Ikaros regulates neutrophil differentiation. Blood 2003;101:2219-26.

18. Christensen AD, Haase C, Cook AD, Hamilton JA. K/BxN serum-transfer arthritis as a model for human inflammatory arthritis. Front Immunol 2016;7:213.

19. Asselin-Paturel C, Brizard G, Pin JJ, Briere F, Trinchieri G. Mouse strain differences in plasmacytoid dendritic cell frequency and function revealed by a novel monoclonal antibody. J Immunol 2003;171:6466-77.

20. Blasius AL, Giurisato E, Cella M, Schreiber RD, Shaw AS, Colonna M. Bone marrow stromal cell antigen 2 is a specific marker of type I IFN-producing cells in the naive mouse, but a promiscuous cell surface antigen following IFN stimulation. J Immunol 2006;177:3260-5.

21. Monach PA, Verschoor A, Jacobs JP, Carroll MC, Wagers AJ, Benoist C, et al. Circulating C3 is necessary and sufficient for induction of autoantibody-mediated arthritis in a mouse model Arthritis Rheum 2007;56:2968-74. 
22. Swiecki M, Gilfillan S, Vermi W, Wang Y, Colonna M. Plasmacytoid dendritic cell ablation impacts early interferon responses and antiviral NK and $\mathrm{CD}^{+} \mathrm{T}$ cell accrual. Immunity 2010;33:955-66.

23. Urosevic M, Dummer R, Conrad C, Beyeler M, Laine E, Burg $\mathrm{G}$, et al. Disease-independent skin recruitment and activation of plasmacytoid predendritic cells following imiquimod treatment. J Natl Cancer Inst 2005;97:1143-53.

24. Glitzner E, Korosec A, Brunner PM, Drobits B, Amberg N, Schonthaler HB, et al. Specific roles for dendritic cell subsets during initiation and progression of psoriasis. EMBO Mol Med 2014;6:1312-27.

25. Kollias G. TNF pathophysiology in murine models of chronic inflammation and autoimmunity. Semin Arthritis Rheum 2005;34 Suppl 1:3-6.

26. De Filippo K, Dudeck A, Hasenberg M, Nye E, van Rooijen N, Hartmann K, et al. Mast cell and macrophage chemokines CXCL1/CXCL2 control the early stage of neutrophil recruitment during tissue inflammation. Blood 2013;121:4930-7.

27. Szekanecz Z, Koch AE. Successes and failures of chemokinepathway targeting in rheumatoid arthritis. Nat Rev Rheumatol 2016;12:5-13.

28. Drobits B, Holcmann M, Amberg N, Swiecki M, Grundtner R, Hammer M, et al. Imiquimod clears tumors in mice independent of adaptive immunity by converting pDCs into tumor-killing effector cells. J Clin Invest 2012;122:575-85.

29. Martinez FO, Gordon S. The M1 and M2 paradigm of macrophage activation: time for reassessment. F1000Prime Rep 2014; 6:13.

30. Garcia S, Forteza J, Lopez-Otin C, Gomez-Reino JJ, Gonzalez A, Conde C. Matrix metalloproteinase- 8 deficiency increases joint inflammation and bone erosion in the $\mathrm{K} / \mathrm{BxN}$ serum-transfer arthritis model. Arthritis Res Ther 2010;12:R224.

31. Itoh T, Matsuda H, Tanioka M, Kuwabara K, Itohara S, Suzuki R. The role of matrix metalloproteinase-2 and matrix metalloproteinase-9 in antibody-induced arthritis. J Immunol 2002;169:2643-7.

32. Singh A, Rajasekaran N, Hartenstein B, Szabowski S, Gajda M, Angel P, et al. Collagenase-3 (MMP-13) deficiency protects C57BL/6 mice from antibody-induced arthritis. Arthritis Res Ther 2013;15:R222.

33. Higgs BW, Liu Z, White B, Zhu W, White WI, Morehouse C, et al. Patients with systemic lupus erythematosus, myositis, rheumatoid arthritis and scleroderma share activation of a common type I interferon pathway. Ann Rheum Dis 2011;70:202936.

34. Van der Pouw Kraan TC, Wijbrandts CA, van Baarsen LG, Voskuyl AE, Rustenburg F, Baggen JM, et al. Rheumatoid arthritis subtypes identified by genomic profiling of peripheral blood cells: assignment of a type I interferon signature in a subpopulation of patients. Ann Rheum Dis 2007;66:1008-14.

35. Cacopardo B, Benanti F, Pinzone MR, Nunnari G. Rheumatoid arthritis following PEG-interferon- $\alpha$-2a plus ribavirin treatment for chronic hepatitis $\mathrm{C}$ : a case report and review of the literature. BMC Res Notes 2013;6:437.

36. Sweeney SE, Corr M, Kimbler TB. Role of interferon regulatory factor 7 in serum-transfer arthritis: regulation of interferon- $\beta$ production. Arthritis Rheum 2012;64:1046-56.
37. Tak PP, Hart BA, Kraan MC, Jonker M, Smeets TJ, Breedveld FC. The effects of interferon $\beta$ treatment on arthritis. Rheumatology (Oxford) 1999;38:362-9.

38. Smeets TJ, Dayer JM, Kraan MC, Versendaal J, Chicheportiche $\mathrm{R}$, Breedveld FC, et al. The effects of interferon- $\beta$ treatment of synovial inflammation and expression of metalloproteinases in patients with rheumatoid arthritis. Arthritis Rheum 2000;43: $270-4$.

39. Jongbloed SL, Benson RA, Nickdel MB, Garside P, McInnes IB, Brewer JM. Plasmacytoid dendritic cells regulate breach of selftolerance in autoimmune arthritis. J Immunol 2009;182:963-8.

40. Jongbloed SL, Lebre MC, Fraser AR, Gracie JA, Sturrock RD, Tak PP, et al. Enumeration and phenotypical analysis of distinct dendritic cell subsets in psoriatic arthritis and rheumatoid arthritis. Arthritis Res Ther 2006;8:R15.

41. Magnusson M, Zare F, Tarkowski A. Requirement of type I interferon signaling for arthritis triggered by double-stranded RNA. Arthritis Rheum 2006;54:148-57.

42. Ying F, Chalise JP, Narendra SC, Magnusson M. Type I IFN protects against antigen-induced arthritis. Eur J Immunol 2011; 41:1687-95.

43. Asquith DL, Miller AM, McInnes IB, Liew FY. Animal models of rheumatoid arthritis. Eur J Immunol 2009;39:2040-4.

44. Wright HL, Moots RJ, Edwards SW. The multifactorial role of neutrophils in rheumatoid arthritis. Nat Rev Rheumatol 2014; 10:593-601.

45. Wu HJ, Sawaya H, Binstadt B, Brickelmaier M, Blasius A, Gorelik L, et al. Inflammatory arthritis can be reined in by $\mathrm{CpG}$ induced DC-NK cell cross talk. J Exp Med 2007;204:1911-22.

46. Spinelli L, Carpentier S, Montanana Sanchis F, Dalod M, Vu Manh TP. BubbleGUM: automatic extraction of phenotype molecular signatures and comprehensive visualization of multiple gene set enrichment analyses. BMC Genomics 2015;16:814.

47. Blazek K, Eames HL, Weiss M, Byrne AJ, Perocheau D, Pease $\mathrm{JE}$, et al. IFN- $\lambda$ resolves inflammation via suppression of neutrophil infiltration and IL-1 $\beta$ production. J Exp Med 2015; 212:845-53.

48. Strieter RM, Burdick MD, Gomperts BN, Belperio JA, Keane MP. CXC chemokines in angiogenesis. Cytokine Growth Factor Rev 2005;16:593-609.

49. Duraes FV, Lippens C, Steinbach K, Dubrot J, Brighouse D, Bendriss-Vermare $\mathrm{N}$, et al. pDC therapy induces recovery from EAE by recruiting endogenous pDC to sites of CNS inflammation. J Autoimmun 2016;67:8-18

50. Yang JY, Kim MS, Kim E, Cheon JH, Lee YS, Kim Y, et al. Enteric viruses ameliorate gut inflammation via Toll-like receptor 3 and Toll-like receptor 7 -mediated interferon- $\beta$ production. Immunity 2016;44:889-900.

51. Bell GM, Anderson AE, Diboll J, Reece R, Eltherington O, Harry RA, et al. Autologous tolerogenic dendritic cells for rheumatoid and inflammatory arthritis. Ann Rheum Dis 2017;76:227-34.

52. Yokogawa M, Takaishi M, Nakajima K, Kamijima R, Fujimoto C, Kataoka S, et al. Epicutaneous application of Toll-like receptor 7 agonists leads to systemic autoimmunity in wild-type mice: a new model of systemic lupus erythematosus. Arthritis Rheumatol 2014 66:694-706. 